\title{
Boron Isotopes in Italian melt inclusions
}

\author{
NATASCIA LUCIANI ${ }^{1}$, IGOR K. NIKOGOSIAN ${ }^{1}$, JAN DE \\ HOOG $^{2}$, GARETH R DAVIES ${ }^{1}$ AND JANNE M. \\ KOORNNEEF $^{1}$
}

\author{
${ }^{1}$ Vrije Universiteit \\ ${ }^{2}$ The University of Edinburgh \\ Presenting Author: n.luciani@vu.nl
}

The composition of $\delta^{11} \mathrm{~B}$ can be used to study the cycling of volatile elements within Earth's interior. Due to its incompatibility and high mobility in aqueous fluids boron provides a powerful tool to better understand fluid-related crustal recycling processes in subduction zones. Across-arc profiles in arc lavas show that the concentration of $\mathrm{B}$ decreases with increasing slab depth and decreasing amount of slab-derived fluids. The two stable isotopes ${ }^{10} \mathrm{~B}$ and ${ }^{11} \mathrm{~B}$ fractionate in the fluids, leading the heavier ${ }^{11} \mathrm{~B}$ to concentrate in the fluid itself [1].

Melt inclusions (MIs) in high-forsterite olivine potentially preserve primary mantle-derived elemental concentrations and isotopic signatures and can record the B isotopic composition of the surrounding melt at the time of trapping. The complex Italian post-collisional subduction setting represents an excellent natural laboratory to study subduction recycling. The magmatic products vary from potassic and ultrapotassic along the Tyrrhenian side in the north to calc-alkaline and Na-alkaline in the south. This diversity reflects the changing geodynamic setting and related major crustal recycling creating a heterogeneous mantle source along the subduction zone. Olivine-hosted MIs from across Italy reveal that primary melts tap this heterogeneous mantle including subducted oceanic and continental components that were introduced during the Alpine, and/or Adriatic and Ionian subduction phases [2-4].

We present boron isotope compositions in 100 selected melt inclusions from a wide range of Italian lavas. The MIs are characterised for major and trace elements and include primary melts representing the different end-members for each of the magmatic Italian provinces as well as within single magmatic series. We will focus on the relation between major- and trace elements and boron isotope compositions to reveal the diversity of subduction-derived metasomatic agents in the Italian mantle that are the sources of the variable K-rich and $\mathrm{Na}-\mathrm{Ca}$ alkaline melts.

[1] De Hoog \& Savov (2018). Boron Isotopes, 217-247.

[2] Nikogosian \& van Bergen, M. J. (2010). Journal of Volcanology and Geothermal Research, 197(1-4), 279-302.

[3] Nikogosian et al. (2016). EPSL, 449, 12-19.

[4] Koornneef et al. (2019). Nature communications, 10(1), 110. 